\title{
Cutaneous B Lymphoblastic Leukemia/Lymphoma
}

National Cancer Institute

\section{Source}

National Cancer Institute. Cutaneous B Lymphoblastic Leukemia/Lymphoma. NCI

Thesaurus. Code C45241.

B lymphoblastic leukemia/lymphoma that arises from the skin. 